\title{
Dependence of the boiler flue gas losses on humidity of wood biomass
}

\author{
LADISLAV DZURENDA ${ }^{1}$ \\ ADRIÁN BANSKI
}

Technical University in Zvolen, Faculty of Wood Sciences and Technology, T.G. Masaryka 24, 96053 Zvolen, Slovakia

\begin{abstract}
The paper analyzes the influence of humidity of combusted wood biomass on the flue gas losses. A mathematical relation between flue gas losses of the boiler on wood biomass humidity is presented as well as temperature of flue gas emitted from the boiler into the atmosphere. The limits of model application for the humidity of wood biomass falls into the interval 10-60\% whereas the range of temperatures of flue gases emitted from the boiler to the atmosphere is $120-200{ }^{\circ} \mathrm{C}$. The influence of the humidity of wood biomass has an adverse effect on increasing the extent of the boiler flue gas losses and thus inefficiency of the heat production. The increase of the wood biomass humidity from the value of $10 \%$ to $60 \%$ with the outlet temperature of flue gases from the boiler $120^{\circ} \mathrm{C}$ causes an increase in flue gas loss of the boiler from the value $8.37 \%$ to $12.43 \%$, similarly the increase of flue gas loss by $200{ }^{\circ} \mathrm{C}$ from $15.19 \%$ to $22.55 \%$, or the increase of the flue gas loss by $7.36 \%$.
\end{abstract}

Keywords: Boiler; Woody biomass; Humidity; Combustion; Flue gas loss

\section{Nomenclature}

$A \quad-\quad$ ratio by weight of the ash content in fuel, $\%$

\footnotetext{
${ }^{1}$ Corresponding Author. E-mail: dzurenda@tuzvo.sk
} 


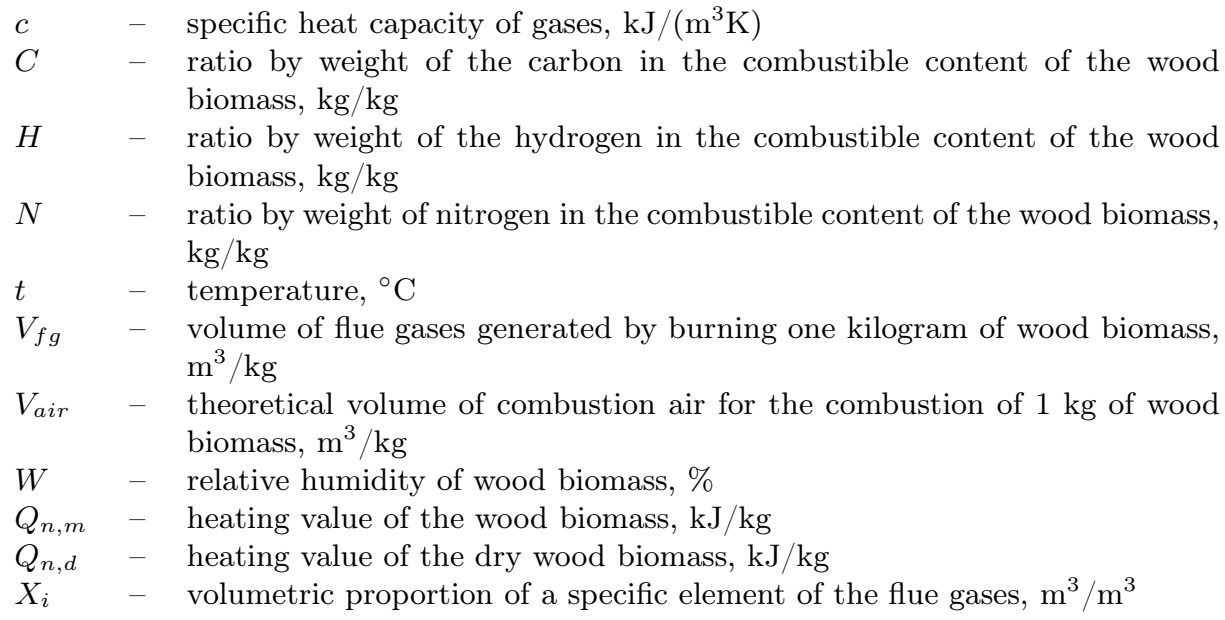

\section{Greek symbols}

$\lambda-$ coefficient of the excess of the combustion air, $\mathrm{m}^{3} / \mathrm{m}^{3}$

$\xi \quad-\quad$ flue gas loss, \%

\section{Subscripts and superscripts}

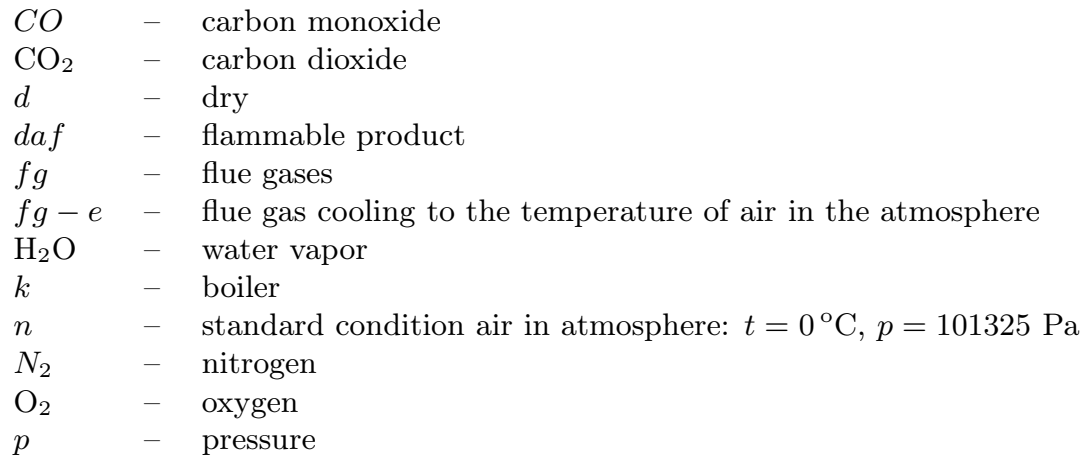

\section{Introduction}

According to the papers [1-9] the efficiency of heat production from the wood biomass depends on both the design of the heat generator, and the energy properties of wood biomass. Energy properties of the wood biomass are significantly dependent on its humidity content, which adversely affects not only the basic energy properties of biomass, such as combustion heat, $Q_{g r}$, and heating value, $Q_{n}$, but also affects the combustion process in the furnace, namely flame temperature, volume of the produced flue gas, temperature of the dew point of flue gas. The use of flue gas heat content - the 
rate of cooling of the flue gases prior to their diversion into the atmosphere and thus the volume of the flue gas loss is dependent on the design solutions of the exchanger of heat generator. Nowadays, the boilers for combustion of wood biomass with medium output reach the thermal efficiency of $75-85 \%$ and modern wood-fired boiler units with guaranteed energy properties reach the efficiency $92 \%$. According to $[10,11]$ the standard boiler heat losses are: flue gas loss, loss in the form of a volatile matter and combustible in solid residues (which are also called the chemical and mechanical unburned products), loss by thermal radiation and convection of heat from the surface of the boiler and finally the operating losses.

The flue gas loss in boilers utilising combustion of fosssil fuels and biofuels are the biggest losses. For this reason, as shown in the works [11-16] in the past and the present, these losses focus most of attention. The present paper presents the analysis of the impact of wood biomass humidity on the flue gas loss in the heat generator and proves the functional dependence of the flue gas loss of heat generators on humidity of wood biomass and on the temperature of flue gases emitted into the atmosphere.

\section{The model}

Flue gas loss, $\left(\xi_{k}\right)$, is the heat loss in the boiler caused by the release of heated flue gas from the boiler into the atmosphere. It is defined as the difference between the enthalpy of flue gases on the output from the boiler and enthalpy of flue gas cooling them to the temperature of air to the amount of heat emitted in $1 \mathrm{~kg}$ of fuel. It is given by the following formula $[10,11]:$

$$
\xi_{k}=\frac{V_{f g} c_{p}^{s}\left(t_{f g}-t_{f g-e}\right)}{Q_{n, m}} \times 100 \%
$$

The algorithm for calculations of parameters of the flue gas loss based on the chemical composition of the combustible, ash content, relative humidity of the combustion wood biomass and combustion excess air is described by the following equations:

- The volume of vaporised flue gases, depending on the chemical composition of the combustible, ash content and humidity is described by the equation [17], or respectively by the graphic representation of that relation on the humidity of wood biomass, Fig. 1. The calculation does not take into account the volume of small amounts of water 
vapor in air into the process of combustion of fuel wood.

The calculation takes into volume of flue gas the following terms:

$$
\begin{aligned}
V_{f g} & =\left[1.67 C^{d a f}+11.2 H^{d a f}+0.8 N^{d a f}+\right. \\
& \left.+V_{\text {air }}(\lambda-0.21)\right][1-A-W]+1.24 W .
\end{aligned}
$$

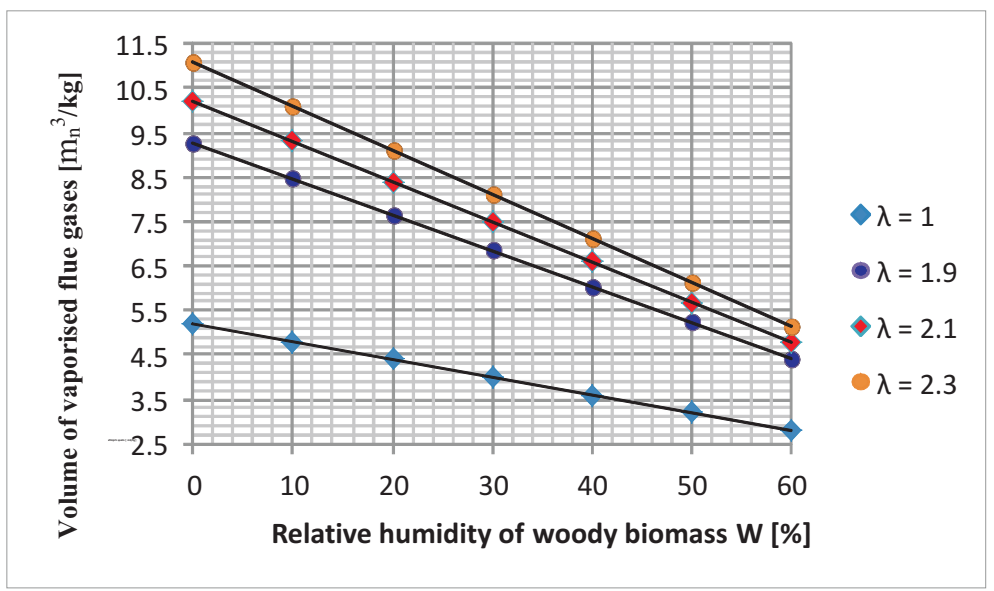

Figure 1: The volume of vaporised flue gases, depending on the humidity content of wood biomass, $W$, at stoichiometric combustion, $\lambda=1$, and at the combustion with the excess of the combustion air $\lambda=1.9$ to 2.3 .

- The mean value of the specific heat capacity of $1 \mathrm{~m}_{n}^{3}$ of the flue gases at a constant pressure is quantified by the equation

$$
\begin{aligned}
c_{p}= & c_{p-C O 2} X_{C O 2}+c_{p-C O} X_{C O}+c_{p-O 2} X_{O 2}+ \\
& +c_{p-N 2} X_{N 2}+c_{p-H 2 O} X_{H 2 O} \quad\left[\mathrm{~kJ} \mathrm{~m}_{n}^{-3} \mathrm{~K}^{-1}\right] .
\end{aligned}
$$

- The volumetric proportions of the individual components in flue gases of woody biomass can be stated based on the following equations:

- The volumetric proportion of carbon dioxide in the flue gas [18]

$$
X_{C O_{2}}=\frac{1.867 C^{d a f}[1-A-W]}{V_{f g}}[-],
$$


Table 1: Values of mean specific heat capacity of $1 \mathrm{~m}_{n}^{3}$ of the flue gas components at a constant pressure [10].

\begin{tabular}{|c|c|c|c|c|c|}
\hline \multirow[t]{2}{*}{ Temperature $\left[{ }^{\circ} \mathrm{C}\right]$} & \multicolumn{5}{|c|}{$\begin{array}{l}\mathrm{c}_{p-i}-\text { mean specific heat capacity of } \\
1 \mathrm{~m}_{n}^{3} \text { of the flue gas component at } \\
\text { a constant pressure }\left[\mathrm{kJ} \mathrm{m}_{n}{ }^{-3} \mathrm{~K}^{-1}\right]\end{array}$} \\
\hline & $\mathrm{CO}_{2}$ & $\mathrm{CO}$ & $\mathrm{O}_{2}$ & $\mathrm{~N}_{2}$ & $\mathrm{H}_{2} \mathrm{O}$ \\
\hline 0 & 1.200 & 1.302 & 1.306 & 1.302 & 1.491 \\
\hline 100 & 1.250 & 1.306 & 1.319 & 1.306 & 1.499 \\
\hline 200 & 1.817 & 1.310 & 1.336 & 1.310 & 1.520 \\
\hline 300 & 1.892 & 1.319 & 1.357 & 1.315 & 1.537 \\
\hline
\end{tabular}

- The volumetric proportion of nitrogen in the flue gas [18]

$$
X_{N_{2}}=\frac{\left(0.8 N^{d a f}+0.79 V_{\text {air }}\right) \lambda[1-A-W]}{V_{f g}}[-],
$$

- The volumetric proportion of oxygen in the flue gas [18]

$$
X_{O_{2}}=\frac{\frac{V_{a i r}}{0.21}(\lambda-1)[1-A-W]}{V_{f g}}[-] .
$$

- The volumetric proportion of water vapour in the flue gas [18]

$$
X_{H_{2} O}=\frac{11.2 H^{\text {daf }}[1-A-W]+1.24 W}{V_{f g}} \quad[-] .
$$

- Theoretical volume of combustion air for the combustion of $1 \mathrm{~kg}$ of woody biomass

$$
V_{\text {air }}=\frac{1}{0.21}\left[1.87 C^{d a f}+5.6 H^{d a f}+0.8 N^{d a f}-0.7 O^{d a f}\right] \quad\left[\mathrm{m}^{3} / \mathrm{kg}\right] .
$$

- Heating value of the biomass depending on the humidity is quantified by the authors $[3,19,20]$ as follows

$$
Q_{n, m}=Q_{n, d}(1-W)-2433 W \quad\left[\mathrm{~kJ} \mathrm{~kg}^{-1}\right] .
$$

- Flue gas temperature, $t_{f g}$, emitted from the boiler into the atmosphere depends on the design of the exchanger of the heat generator, and the 
rate of cooling of the flue gases. Current renowned manufacturers of boilers for combustion of fuel - biomass (Herz GmbH, Vyncke Energietechniek n.v., TTS Group Třebič) guarantee cooling of the flue gases to the temperature range: $120-200{ }^{\circ} \mathrm{C}$.

\section{The results}

The application of the given mathematical model which analyzes the impact of biofuel humidity on the boiler flue gas loss is realized for wood biomass with the chemical composition of the combustible: $C^{\text {daf }}=0.5 \pm 0.01 \mathrm{~kg}$ $\mathrm{kg}^{-1}, H^{d a f}=0.06 \pm 0.001 \mathrm{~kg} \mathrm{~kg}^{-1}, O^{d a f}=0.44 \pm 0.03 \mathrm{~kg} \mathrm{~kg}^{-1}$, the ash content in wood $A^{d}=0.01 \mathrm{~kg} \mathrm{~kg}^{-1}$.

Table 2 shows the heating values, the volume of vaporised flue gases and the heat loss of the boiler for combustion of woody biomass in the range of relative humidity $W=10-60 \%$, at the excess of combustion air $\lambda=2.1$ and at the average temperature of the combustion air emitted into the boiler furnace $t_{\text {air }}=10^{\circ} \mathrm{C}$ and finally the temperatures of flue gases in the outlet of the heat generator $t_{f g}=120^{\circ} \mathrm{C}$ and $200^{\circ} \mathrm{C}$.

Table 2: Flue gas loss of boiler for outlet temperatures of flue gases $t_{f g}=120^{\circ} \mathrm{C}$ and $t_{f g}=200^{\circ} \mathrm{C}$ on dependence humidity woody biomass.

\begin{tabular}{|l|c|c|c|c|c|c|c|}
\hline \multirow{2}{*}{ Parameter } & \multirow{2}{*}{ Unit } & \multicolumn{6}{|c|}{ Humidity of the biofuel W [\%] } \\
\cline { 3 - 8 } & & 10 & 20 & 30 & 40 & 50 & 60 \\
\hline \hline Heating value of the biofuel & $\mathrm{kJ} \mathrm{kg}^{-1}$ & 16705 & 14569 & 12434 & 10148 & 8163 & 5802 \\
\hline $\begin{array}{l}\text { Volume of vaporised flue } \\
\text { gases }\end{array}$ & $\mathrm{m}_{n}^{3} \mathrm{~kg}^{-1}$ & 9.21 & 8.35 & 7.45 & 6.55 & 5.65 & 4.75 \\
\hline $\begin{array}{l}\text { Heat loss of the flue gases at } \\
\text { temperature: } t_{f g}=120^{\circ} \mathrm{C}\end{array}$ & $\%$ & 8.37 & 8.70 & 9.09 & 9.80 & 10.51 & 12.43 \\
\hline $\begin{array}{l}\text { Heat loss of the flue gases at } \\
\text { temperature: } t_{f g}=200^{\circ} \mathrm{C}\end{array}$ & $\%$ & 15.19 & 15.79 & 16.51 & 17.78 & 19.08 & 22.55 \\
\hline
\end{tabular}

The influence of humidity of combusted wood biomass on the heat flue gas losses is graphically presented in Fig. 2 for flue gas emitted from the boiler into atmosphere with temperature $t_{f g}=120^{\circ} \mathrm{C}$ as well as $200^{\circ} \mathrm{C}$. The analysis of the dependency of the boiler heat loss on wood biomass humidity proves that the impact of the wood biomass humidity in the interval of humidity $W=10-60 \%$ is at the temperature of emitted flue gases 


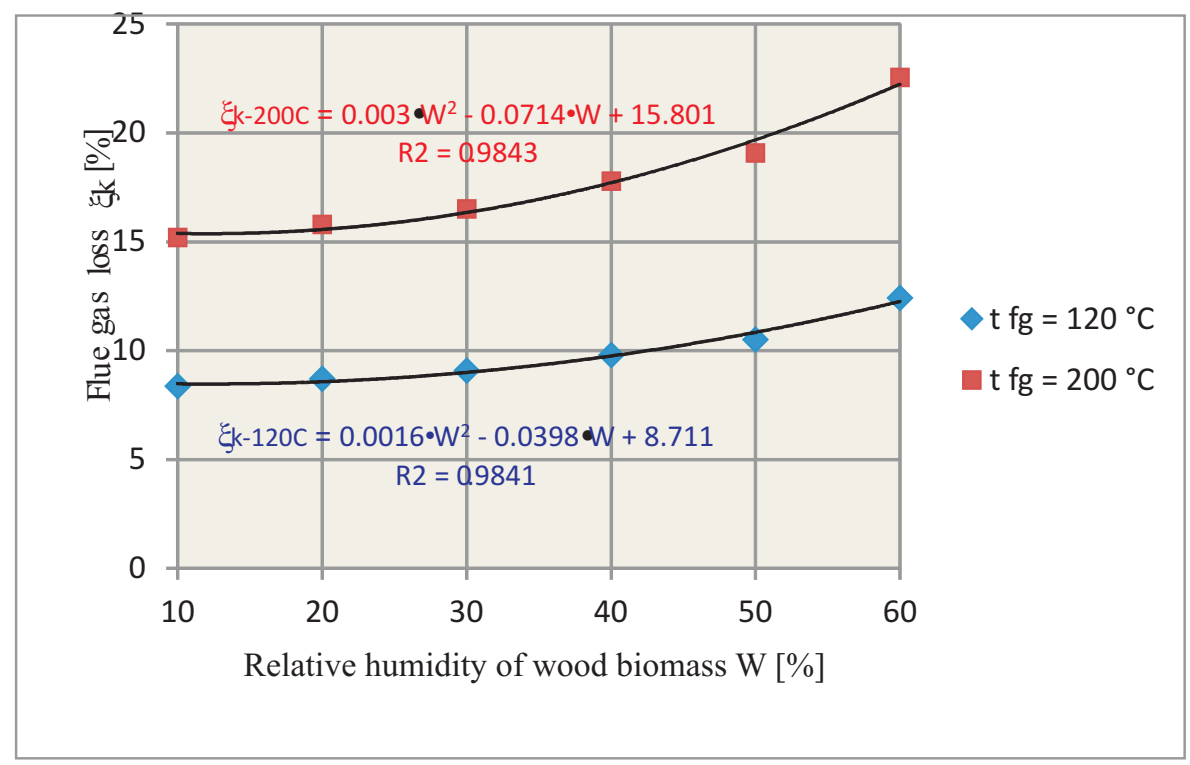

Figure 2: The dependence of flue gas loss on the humidity of wood biomass for flue gas temperature of $120^{\circ} \mathrm{C}$ and $200^{\circ} \mathrm{C}$.

$t_{f g}=120^{\circ} \mathrm{C}$ manifested by increasing the dependence of the humidity effect on the size of wood biomass boiler heat flue gas loss at the flue gas emitted to the atmosphere from $\xi_{k-10 \%}=8.37 \%$ to $\xi_{k-60 \%}=12.43 \%$, i.e., the average increase in humidity by $\Delta W=10 \%$ increases the heat flue gas loss by an average of $\Delta \xi_{k}=0.81 \%$ and at the temperature of emitted flue gases $t_{f g}=200{ }^{\circ} \mathrm{C}$ the boiler heat loss increases from $\xi_{k-10 \%}=15.19 \%$ to $\xi_{k-60 \%}=22.55 \%$, i.e., with an average increase of humidity by $\Delta W=10 \%$ the heat flue gas loss increases on average by $\Delta \xi_{k}=1.47 \%$. The increase in boiler heat loss is caused by the decline in the proportion of combustible in the combusted biofuel and thus by its heating value as well as by the growth in the share of steam supplied to the flue gas from the drying process of the biofuel.

Figure 3 shows the dependence of flue gas loss in the heat generator, $\xi_{k}$, that takes into account the impact of the woody biomass humidity as well as temperature of the flue gas emitted into the atmosphere, for the intervals defined by the boundary conditions: relative humidity $W=10-60 \%$ and temperature of flue gases emitted from the boiler into the atmosphere $t_{f g}=120-200^{\circ} \mathrm{C}$. Functional dependency of heat flue gas loss in the heat 


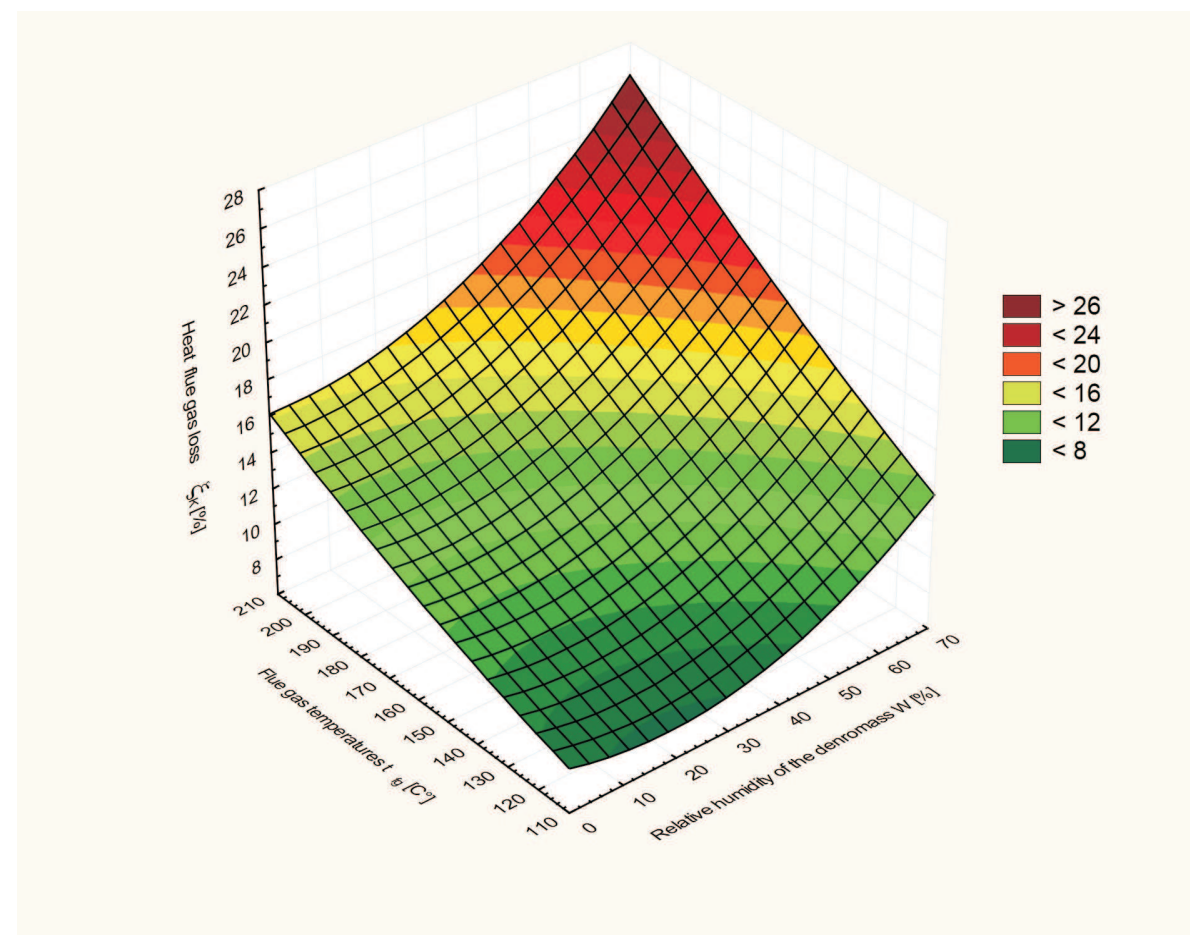

Figure 3: Dependency of the impact of humidity $W=10-60 \%$ and flue gas temperatures $t_{f g}=120^{\circ} \mathrm{C}$ and $200{ }^{\circ} \mathrm{C}$ on the extent of heat flue gas loss in the heat generator $\xi_{k}$.

generator for the combustion of wood biomass on the relative humidity $W=10-60 \%$ and on the temperatures of the flue gases emitted from the generator into the atmosphere $t_{f g}=120-200^{\circ} \mathrm{C}$ is described by the following equation:

$$
\begin{aligned}
\xi_{k}= & 2.1308-0.1675 W+0.0462 t_{f g}+ \\
& +0.0022 W^{2}+0.0008 W t_{f g}+0.0001 t_{f g}^{2} \quad[\%] .
\end{aligned}
$$

The average increase of the heat flue gas loss by $\Delta \xi_{k}=1.14 \%$ with the increase in wood biomass humidity of the combusted wood biomass by $\Delta W=$ $10 \%$ in the boilers which meet the criteria of best available technology (BAT) is a serious argument for reducing humidity in the wood biomass for combustion and for the use of economically effective forms of pre-drying and drying process of wood biomass intended for energy purposes. Such technologies are, for example, transpiration drying of plantation-grown wood 
biomass $[17,20]$ or natural drying process of the logs of firewood in the sheltered warehouses [23].

\section{Conclusions}

In this paper, there is presented a dependency of the flue gas loss in the boiler on the humidity of the combusted wood biomass and the temperatures of the emitted flue gases from the boiler into the atmosphere. The dependency, Eq. (10), is formulated for given boundary conditions: relative humidity of the combusted woody biomass: $10-60 \%$ and the temperature of combustion gases emitted into the atmosphere $120-200{ }^{\circ} \mathrm{C}$.

Increase in the humidity of wood biomass from $10 \%$ to $60 \%$ at the temperature of emitted flue gases $120^{\circ} \mathrm{C}$ is projected in the increase in heat flue gas loss by $\Delta \xi_{k-w}=4.05 \%$ and at the temperature of the emitted flue gases $200^{\circ} \mathrm{C}$ in the increase in heat flue gas loss by the value $\Delta \xi_{k-w}=7.36 \%$.

Increasing of the wood biomass humidity by $\Delta \mathrm{W}=10 \%$ is negatively reflected in increase of the heat flue gas loss of the boiler by an average of $\Delta \xi_{k}=1.14 \%$.

Acknowledgments The present contribution was developed under the research of a grant project: KEGA-SR No: 006TU Z-4/2014, as a result of the work of the authors and a significant assistance of the Cultural and Educational Grant Agency of the Ministry of Education, Science, Research and Sport of the Slovak Republic (KEGA-SR).

Received 30 May 2015

\section{References}

[1] Golonkov S.I., Koperin I.F., Najdenov V.I.: Energy Use of Wood of Wastes. Moscow 1987 (in Russian).

[2] Marutzky R., Seeger K.: Energy from Wood and other Biomass. DRD - Verlag Weinbrenner GmbH and Co., Leinfelden-Echterdingen 1999 (in German).

[3] Domanski M., Dzurenda L., Jablonski M., Osipiuk J.: Wood as a Material Energetic. SGGW, Warsaw 2007 (in Polish).

[4] Malẵák J., Vaculík P.: Biomass for Energy Production. CZU, Praha 2008 (in Czech).

[5] Dobrowolska E., Dzurenda L., Jablonski M., Klosinska T.: Energy Utilization of Dendromas. SGGW, Warsaw 2010 (in Polish). 
[6] Picchio R., Spina R., Sirna A., Lo Monaco A., Civitarese V., Del Giudice A., SuArdi A., PARI L.: Characterization of woodchips for energy from forestry and agroforestry production. Energies 5(2012), 10, 3803-3816.

[7] JandaČKa J., HolubČík M., Malcho M., Nosek R.: Modification of wood pellets parameters by using of concentrate of organic compounds from defibration. Acta Facultatis Xylologiae Zvolen 52(2013), 2, 105-115 (in Slovak).

[8] ZięBik A., GŁadysz P.: Influence of biomass cofiring on the optimal coefficient of the cogeneration share in a district heating system. Arch. Thermodyn. 35(2014), 1, 99-115, DOI: 10.2478/aoter-2014-0007.

[9] Dzurenda L., Ladomerský J., Hroncová E.: Conversion factor of fuel-bound nitrogen to oxides in the process of spruce wood combustion in boiler grate furnaces. Pol. J. Environ. Stud. 24(2015), 2, 505-509.

[10] Rajniak I. et al.: Thermo- Energetic and Emission Measurements. Ister Science, Bratislava 1997 (in Slovak).

[11] Holoubek D.: Combustion Equipment, Heat Exchangers and Boilers. Ars Litera, Košice 2002, (in Slovak).

[12] TrnobranskÝ: The possibility of using waste heat for boilers burning wood waste. Drevo 44(1989), 77-78 (in Czech).

[13] GLiJer L.: Technique and heat management in the wood industry. Wyd. SGGW, Warsaw 1992 (in Polish).

[14] Neuenschwander P., Good J., Nussbaumer Th.: Combustion efficiency in biomass furnaces with flue gas condensation. In: Proc. 10th European Conference and Technology Exhibition Biomass for Energy and Industry, June 8-11, 1998.

[15] Dzurenda L., Dobrowolska E.: Heat losses while maintaining ekological combustion conditions. Przemysl drzewny 7-8(2003), 28-30 (in Polish).

[16] TTS group Třebič http://www.tts.cz/cz/boilers/spalinovy-kondenzator.html (accessed on 18.02.2015).

[17] Dzurenda L., Banski A., Šustek J.: Dendromass - Biofuel for Heat and Electricity. TU Zvolen, Zvolen 2015 (in Slovak).

[18] Dzurenda L., JandaČka J.: Energy utilization of dendromass. TU Zvolen, Zvolen 2010 (in Slovak).

[19] Kollmann F.: Technology of Wood and Wood-Based Materials. I. Band. BerlinGöttingen-Heidelberg-Munchen 1951 (in German).

[20] Simanov V.: Energy Use of Wood. Olomouc, Terapolis 1995 (in Czech).

[21] JandaČKa J., Malcho M., Mikulík M.: Technologies for the Preparation and Energy Uses of Biomass. GEORG, Žilina 2007 (in Slovak). 